\title{
A conceptual stages-of-growth model for managing a social media business profile
}

Research Article

\author{
Aidan Duane ${ }^{1 *}$ and Philip O'Reilly² \\ 'Waterford Institute of Technology, Waterford, Ireland \\ ¿University College Cork, Cork, Ireland
}

\begin{abstract}
There is little understanding of how organisations manage social media. Stage-of-growth (SoG) models represent a picture of evolution, where the current stage can be understood in terms of history and future, providing an opportunity to identify the stages, paths of evolution, benchmark variables, and dominant problems experienced by organisations at each stage. Following a review of 4 decades of SoG model research, as well as a review of existing social media research and practitioner insight across multiple domains, the authors adopt Gottschalk and Solli-Sæther's (2010) five-step stage modelling process as a research methodology to develop a SoG model for managing a social media business profile (SMBP). The paper develops and validates Step 1 (suggested stage model) and Step 2 (conceptual stage model) of the stage modelling process. A number of key contributions to theory and practice are identified, and ongoing research to further refine the model is outlined.
\end{abstract}

Keywords: social media; information system management; stages of growth; dominant problems

(C) De Gruyter Open Sp. z 0.0 .

\section{INTRODUCTION}

Social media are used by organisations for marketing, advertising, public relations, recruitment, research, product/ service testing and review, idea generation, feedback, and occasionally, complaint handling (Aggarwal et al., 2011; Aral et al., 2013). However, this has 'barely scratched the surface of what is coming and what is possible' (Aral et al., 2013: 3). There is 'growing importance of social media as a strategic tool among organisations' (Parveen, 2012: 3 ), as it can revolutionise how organisations engage with the market and society, creating new enterprise-wide possibilities and challenges ranging from marketing and operations, to finance and human resource management (Aral et al., 2013).

Parveen (2012: 2) suggests 'there is lack of understanding in terms of how social media benefits the organisation'. According to Aral et al. (2013: 4), 'there is no agreement with respect to how responsibility for social media should be allocated within organisations, how social media activities should be funded and governed, what should be outsourced, and what broader changes with regard to an organisation's structures, processes, leadership, training, and culture are needed to harness the potential of this transformative force'. More importantly, there is no established 'path of activities' that guide a company down the path of 'social readiness' and there are 'no widely accepted industry-specific best practices' (Aral et al., 2013: 4). There is a dearth of peer-reviewed research focussing on social media management (Aral et al., 2013).

This paper aims to address this lack of research by developing a conceptual stages-of-growth (SoG) model for managing a social media business profile (SMBP). Extant research of SoG models reveals a wealth of knowledge regarding the management of information systems (ISs) as they evolve and mature. SoG models provide an opportunity to identify the stages, the paths of evolution, the benchmark variables, and the dominant problems experienced at each stage (Gottschalk and Solli-Sæther, 2010). Gottschalk and Solli-Sæther (2010) recognised that researchers struggle to develop SoG models that are theoretically founded and empirically validated and, in 
response, developed a five-step stage modelling process, which the authors have adopted. The paper continues with a review of extant research of SoG models, including more recent SoG models for social media, and a review of the dominant problems associated with social media.

\section{LITERATURE REVIEW}

SoG models have been widely used to identify mechanisms for managing ISs as they evolve. The names of stages and the benchmark variables by which they are measured differ to some extent, as is evident from the plethora of SoG models that have been developed over the past 40 years. However, all SoG models purport that ISs evolve through a number of stages, with respect to their use and management, and increase in sophistication and complexity as their application becomes more significant and mission critical (Chan and Swatman, 2004; Damsgaard and Scheepers, 1999; de Brí, 2009; de Bruin et al., 2005; Duane and Finnegan, 2003; Earl, 1989; Forrester, 2012; García et al., 2013; Gibson and Nolan, 1974; Gottschalk and Khandelwal, 2004; Gottschalk and Solli-Sæther, 2010; Jacobs and Nakata, 2010; Janssen and van Veenstra, 2005; Jayasuriya, 1993; Jeffery and Leliveld, 2004; Kazanjian, 1988; King and Teo, 1997; KPMG, 1997; Layne and Lee, 2001; Lingling, 2011; Magal et al., 1988; McFarlan and McKenney, 1982; Nikhil et al., 2007; Rao et al., 2003; Rocha, 2012). The following sections discuss the development and use of SoG models over the past 40 years, including recent SoG models for social media, before discussing the dominant problems associated with social media.

\section{Stages-of-growth (SoG) models}

The earliest four-stage model was developed by Gibson and Nolan (1974). It was further refined as a six-stage model by Nolan (1979). The model emphasises the need for management strategy to be consistent with the organisation's stage with respect to technology (Galliers and Sutherland, 1991). McFarlan and McKenney (1982) proposed a four-stage model, arguing that it is not necessary to work through all elements of all stages, implying it is possible to select which aspects of IS management to move forward on. Rao et al. (2003) found empirical evidence to support the validity of McFarlan and McKenney's (1982) SoG model but could not support the specific stages. Earl (1989) proposed a five-stage model, arguing that organisations would have different learning curves for different ISs. However, Galliers and Sutherland (1991) criticise the model, suggesting that it only places an organisation at a certain stage without actually suggesting how the organisation moves to a more mature stage. Galliers and Sutherland (1991) propose a model that describes the stages through which an organisation evolves with respect to use of information technology (IT) and indicates how organisations can move from the initial stages to an advanced stage of maturity. However, Brugha (1998) disputes this approach and suggests that it is more beneficial to focus on activities rather than outputs, as they are less contextual and because activities provide decision makers with better indicators of what to do at each stage. Numerous other authors have proposed theoretical stages of IS growth models based on these models for a variety of purposes, including end user computing (Huff et al., 1988; Jayasuriya, 1993), information centres (Magal et al., 1988), technology-based new ventures (Kazanjian, 1988), IS planning (King and Teo, 1997) and IT portfolio management (Jeffery and Leliveld, 2004), and for the most part, empirical testing of the stages proposed in these models has been positive.

The advent of e-business has heralded the development of several new SoG models. McKay et al. (2000) propose a model of e-business implementation called the SoG-e, which integrates Galliers and Sutherland's (1991) SoG model to depict activities based on an organisation's Internet technologies, as well as its traditional IS. The SoG-e presumes a progression of levels as the organisation accumulates knowledge, experience, qualifications, and expertise in e-business. By contrast, Rayport and Jaworski (2002) suggest a four-stage model of the evolution of business-to-business (B2B) e-commerce, but the model is now considered flawed (Ghachem, 2006). Rao et al. (2003) also propose a SoG model for e-commerce, comprising four phases. Similar to McFarlan and McKenney (1982), Rao et al. (2003) propose that organisations do not need to accomplish each stage successfully; organisations can begin in any phase, skipping certain stages; and, an organisation that is increasingly aware of IT and e-commerce could begin with a later maturity phase. While some researchers such as Lingling (2011) and Rocha (2012) support the notion that organisations can select which aspects of the technology to move forward on, Lingling (2011) argues that stages cannot be skipped because the experience learned from the previous stage is necessary for the next stage. Chan and Swatman (2004) found that only two growth types, namely, (i) strategy and objectives and (ii) focus of the implementation, were consistent when examined empirically across several 
cases. SoG models have also been adopted by Hinrichs (1997), KPMG (1997), Damsgaard and Scheepers (1999), and Duane and Finnegan (2003), to explore the evolution of Intranets in organisations. Similar to McFarlan and McKenney (1982), Damsgaard and Scheepers (1999) suggest that progression can be made even though not all elements are strictly in the same phase, and stages can be skipped. Duane and Finnegan (2003) found that Intranets develop organically in early stages, evolve rapidly to become critical for day-to-day operations, extend to integrate the external value chain and, similar to the Galliers and Sutherland (1991) SoG model, finally become institutionalised in the organisation. Watson et al. (2001) developed a data warehousing SoG model based on Nolan (1979), asserting that by understanding the stage, management would be better able to plan and would be better positioned to avoid any pitfalls. Gottschalk and Khandelwal (2004) developed a four-stage knowledge management technology (KMT) model, which was followed by de Bruin et al. (2005), who developed a six-stage (Levels 0-5) Knowledge Management Capability Assessment (KMCA) model, and Nikhil et al.'s (2007) five-level SoG model. SoG models have also emerged in e-Government and IS in healthcare and education. Layne and Lee (2001) developed a four-stage e-Government SoG model, and similar work by Janssen and van Veenstra (2005) focussed on a five-stage SoG model for information architectures in local governmental agencies. Janssen and van Veenstra (2005) suggest that organisations sometimes concatenate stages, and the number of stages may expand as technological advances are made, or discontinuities occur, and a new SoG model may be required. This perspective is similar to that of Watson et al. (2001), who reveal that advances in data warehousing led to revision of their SoG model. e-Government SoG models were later extended into a seven-stage model by de Brí (2009), who recommends the stage adoption once there is consensus that there is value in moving forward. The model also suggests that stages may be skipped. Rocha (2012) devised a SoG model to manage the evolution of IS in healthcare. García et al. (2013) developed a five-stage SoG model for IT service outsourcing in higher education. Arguably, the model builds on Adelakun's (2004) five-stage and Gottschalk and Solli-Sæther's (2006) three-stage maturity models for IT outsourcing, but neither model was tested.

\section{Social media SoG models}

Social media has become a very important research topic in both personal and corporate contexts (Aral et al., 2013; Levina and Yavetz, 2013). However, to date, very little research has been conducted on organisational use and management of social media (Parveen, 2012). This may be because organisational adoption of social media is slow compared to the growth of social media for personal purposes (Baltatzis et al., 2008). Barnes and Lescault (2011: 2) even suggested that adoption of social media by organisations 'has levelled off or fallen'. However, the SoG literature has been extended by the emergence of two new models that pertain to the field of Web 2.0 and social media in particular. Jacobs and Nakata (2010: 6) propose a SoG model for social media adoption to 'provide a roadmap for improvement' for the planning and development of social media strategy. Heavily influenced by Earl (2000), the six-stage model includes a description of the focus at each stage, but it is a simplistic, non-specific approach to modelling. The model does not identify any mechanism by which progress can be measured, and its paths of evolution are unclear. The model does not identify the management challenges or problems to be overcome at any of the stages, unlike Rao et al. (2003), who identified 'Barriers' and 'Facilitators' at each stage. Gottschalk and Solli-Sæther (2010) argue that all SoG models should identify 'benchmark variables' and 'dominant problems' at each stage. The model is conceptualised on one single SoG model and does not consider the contributions of any other SoG model. Even Earl (2000: 7) describes his proposed model as 'highly idealised', and neither Earl, nor Jacobs and Nakata, have empirically tested their models.

Forrester (2012) propose a five-stage social media maturity model, namely, (i) dormant; (ii) testing; (ii) co-ordinating; (iv) scaling and optimising; and (v) empowering the workforce. However, while Forrester's SoG model and findings are interesting, the model is also confusing, particularly with respect to the 'Dormant stage', which in essence is not a stage at all, as no social media activities occur. The final stage, 'Empowering', is also poorly developed, which may be a symptom of the few organisations that are positioned at this stage, if indeed there are any. In some instances, the model reveals a necessity to separate one variable into two or more variables, such as 'measurement'. Thus, while the Jacobs and Nakata (2010) and the Forrester (2012) models provide stages from which to explore SoG models for managing social media, both models have limitations and need improvement before they are of benefit to organisations. More importantly, the dark side or dominant problems of social media are not adequately addressed in the existing SoG models for managing social media. According to Gottschalk and Solli-Sæther (2010), it is essential for a SoG model to conceptualise the dominant problems. Thus, the paper continues to the next section, wherein the dominant problems associated with social media adoption in organisations are explored. 


\section{Dominant problems associated with social media adoption}

Dominant problems are varied, change from stage to stage and can shift from a lack of skills, to a lack of resources, to a lack of strategy (Gottschalk and Solli-Sæther, 2010). Aral et al. (2013: 5-6) reveal how social media can have 'powerful' and 'surprising effects' on product use and individual and community outcomes, and that 'our intuitions may not always correctly predict social media's consequences'. Often, the consequences are negative as inappropriate postings have unimaginable and unintended consequences for the organisation's public persona and bottom line. Organisations struggle to manage negativity (Aggarwal et al., 2012; Barnes, 2012; Kaplan and Haenlein, 2010; Weber, 2011) directed at it through its SMBP. However, evidence from a multitude of sources (e.g. Aggarwal, 2011; Barnes, 2012; Helms, 2010; Jacobs and Nakata, 2010; Munene and Nyaribo, 2013; Piskorski, 2011; Weber, 2011) suggests that organisations have not developed strategies to manage social media. As social media adoption matures, organisations must 'integrate social media strategies with their overall strategy' (Aral et al., 2013: 8).

Organisations must also be aware that strategies should focus on participation, sharing, and collaboration, rather than just advertising and selling (Kaplan and Haenlein, 2010). Otherwise, goal incongruity and process disconnect occurs as the SMBP fails to match strategic goals, business needs and audience desires (Bradley, 2010; Weber, 2011). Uncoordinated efforts also reduce effectiveness and cause confusion (Forrester, 2012; Piskorski, 2011). Monologue also occurs if stakeholders are not involved in ideation or co-creation (Huang et al., 2011). Ambiguity regarding social media strategy also has a negative impact (Kaplan and Haenlein, 2010), and failing to manage efforts 'may not portray the image the company would like or worse cause damage to their reputation' (Jacobs and Nakata, 2010: 3). Aguenza and Mat Som (2012: 49-50) warn of the 'embarrassment' and 'damage' to reputation by staff misuse of social media. Thus, all stakeholders must learn to use social media to meet their respective objectives (Aral et al., 2013).

Failure to formalise usage policies for internal/external social media use also has unintended consequences (Aggarwal et al., 2011; Bott et al., 2009; Forrester, 2012; Kaplan and Haenlein, 2010; Munene and Nyaribo, 2013; Piskorski, 2011; Ward and Ostrom, 2006). Social media has a 'dark side' that leads to 'abuse, addiction and misuse', reducing productivity, as well as an increasingly 'strained computing and network resource' and 'misrepresentation' due to staff failure to distinguish between personal and business use (Munene and Nyaribo, 2013: 149). Training is a possible solution, but it is a long-term commitment (Bott et al., 2009). Social media also poses significant technological threats (Hong, 2012; Li et al., 2013; Nesbit, 2011), and brand hijacking, squatter accounts and lack of control over content are additional issues (Jacobs and Nakata, 2010). Adoption may also be hindered by a lack of management support (Forrester, 2012). Another problem is a perception that the SMBP does not require additional resources (Bott et al., 2009; Forrester, 2012; Piskorski, 2011). These problems may dissipate as social media matures and organisations overcome the newness factor (Bott et al., 2009). Thus, it may be in the later stages of growth that such a formalisation may occur, which may be because the management is unaware of the extent of use and the negative consequences of misuse, or because of a decision to allow social media use to develop organically at the early stages to establish it as a viable business system. However, it is possible to conceptualise in which stage(s) these problems occur only through empirical analysis (Gottschalk and Solli-Sæther, 2010). In advance of this empirical work, Table 1 summarises the dominant problems emerging from the literature.

Table 1 Dominant problems with organisational use of social media

\begin{tabular}{|c|c|}
\hline \multicolumn{2}{|c|}{ Dominant Problems with Social Media } \\
\hline Lack of an appropriate social media strategy. & Bandwidth issues, especially due to VoD. \\
\hline $\begin{array}{l}\text { Lack of funding or resources. } \\
\text { Duplication due to lack of coordination and direction across multiple } \\
\text { social media platforms. } \\
\text { Disconnect from business functions and processes. }\end{array}$ & $\begin{array}{l}\text { Lack of control over content. } \\
\text { Negative comments, reviews, and feedback from internal and external } \\
\text { detractors. } \\
\text { Brand hi-jacking or cyber-squatting. }\end{array}$ \\
\hline $\begin{array}{l}\text { Increase in viruses/malware attacks. } \\
\text { Failure to listen to/involve stakeholders especially through } \\
\text { crowdsourcing, ideation and co-creation. } \\
\text { Lack of appropriate security controls and polices. }\end{array}$ & $\begin{array}{l}\text { Lack of senior management support and commitment. } \\
\text { Failure to appoint an individual/group to manage and coordinate social } \\
\text { media. }\end{array}$ \\
\hline Incongruity, ambiguity or uncertainty over social media objectives. & $\begin{array}{c}\text { Business social intelligence failures in translating social media data into } \\
\text { strategy. }\end{array}$ \\
\hline Failure to create and enforce formal social media usage policies. & Failure to establish metrics to measure social media ROI. \\
\hline Employee misuse/abuse. & Over-zealous management control of social media. \\
\hline Failure to deliver social media training. & Exposure to lawsuits and legal action. \\
\hline
\end{tabular}




\section{METHODOLOGY}

According to King and Kraemer (1984: 474), 'the goal of future research must be the creation of improved models that avoid the problems evident in the Nolan model'. Rocha (2012: 200) agrees and asserts that 'there is still a way to go for having available widespread and detailed maturity models'. While there are numerous SoG models with a multitude of applications, 'there is little documentation on how to develop a maturity model that is theoretically sound, rigorously tested and widely accepted' (de Bruin et al., 2005: 2). Few models have explicitly detailed how an organisation actually moves forward or transitions to a new stage (Kazanjian, 1988), creating a gap in the literature that can only be filled with empirical research. In this respect, Gottschalk and Solli-Sæther (2010) developed a stage modelling process to analyse SoG models in the context of their development.

\section{The stage modelling process}

Gottschalk and Solli-Sæther's (2010: 280-282) five-step stage modelling process represents a theoretical and an empirical research procedure 'where the object changes its status from a suggested stage model, via conceptual and theoretical stage models, to an empirical stage model, and finally to a revised stage model', as shown in Figure 1. This paper focusses on the development and empirical analysis of a suggested stage model (Step 1) and a conceptual stage model (Step 2).

Figure 1 A stage modelling process (Gottschalk and Solli-Sæther, 2010).

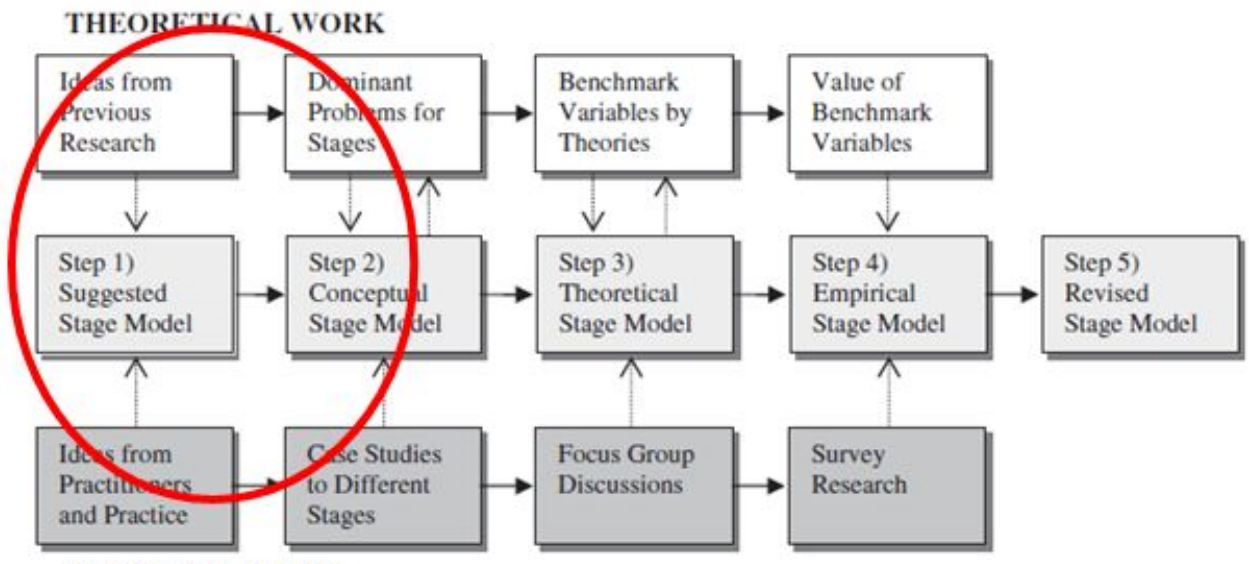

EMPIRICAL WORK

Gottschalk and Solli-Sæther (2010) identified four key topics to analyse a SoG model:

a) Number of stages: Organisational phenomena undergo transformations in their design characteristics that can be defined in terms of discrete stages of growth.

b) Paths of evolution: An organisational phenomenon shows a predictable pattern of development from first stage to second stage, and so on, until it reaches the final stage, either directly or via bypassed or revisited stages.

c) Dominant problems: Dominant problems at each stage of growth will statistically correspond with the conceptual formulations given for that stage.

d) Benchmark variables: Values of benchmark variables for each stage of growth will statistically correspond with the conceptual formulations given for that stage.

The authors apply these topics in Table 2 to analyse the SoG models in the extant literature. This enables identification of the key characteristics of SoG models, which when integrated with extensive reviews of social media research and practitioner insight across multiple domains, enables the authors to ground the study and develop a suggested stage model. 
Table 2 Applying Gottschalk and Solli-Sæther s (2010) four key topics to the extant SoG literature

\begin{tabular}{|c|c|}
\hline Topics & Characteristics \\
\hline \multirow{6}{*}{$\begin{array}{l}\text { Number of } \\
\text { Stages }\end{array}$} & $\begin{array}{l}\text { There is a maturity curve to the adoption of any enabling technology and this evolution can be divided into a number of distinct } \\
\text { stages of growth. }\end{array}$ \\
\hline & Watson et al. (2001); Gottschalk and H. Solli-Sæther (2006). \\
\hline & $\begin{array}{l}\text { Gibson \& Nolan (1974); McFarlan \& McKenney (1982); Kanzanjian (1988); Earl (1989); King and Teo (1997); } \\
\text { Layne and Lee (2001); Rao et al. (2003); Damsgaard \& Scheepers (1999); Chan \& Swatman (2004); Gottschalk } \\
\text { and Khandelwal (2004); Jeffery and Leliveld, (2004); Lingling (2011). }\end{array}$ \\
\hline & $\begin{array}{l}\text { Hinrichs (1997); KPMG (1997); Magal et al. (1988); Jayasuriya, (1993); Adelakun (2004); Janssen \& van Veenstra } \\
\text { (2005); Nikhil et al. (2007); Rocha (2012); García et al. (2013). }\end{array}$ \\
\hline & Galliers \& Sutherland (1991); Earl (2000); McKay et al. (2000); Duane \& Finnegan (2003); de Bruin et al. (2005). \\
\hline & de Brì (2009). \\
\hline $\begin{array}{l}\text { Paths of } \\
\text { Evolution }\end{array}$ & $\begin{array}{l}\text { Paths of evolution vary greatly as organisations: } \\
\text { may not complete each stage; may begin in any phase; and may skip stages (Damsgaard \& Scheepers, 1999; Earl, 2000; Rao } \\
\text { et al., 2003). } \\
\text { may concatenate stages (Watson et al., 2001; Janssen \& van Veenstra, 2005). } \\
\text { may select which aspects of the technology to move forward on (Galliers \& Sutherland, 1991; Duane \& Finnegan, 2003; Lingling, } \\
\text { 2011). } \\
\text { may skip stages (Damsgaard \& Scheepers, 1999; Earl, 2000; Rao et al., 2003; de Brì, 2009) } \\
\text { may have to complete every stage without skipping stages (Lingling, 2011) } \\
\text { may expand the number of stages as technological advances are made (Watson et al., 2001; Janssen \& van Veenstra, 2005). }\end{array}$ \\
\hline $\begin{array}{l}\text { Dominant } \\
\text { Problems }\end{array}$ & $\begin{array}{l}\text { Organisations may experience different dominant problems at each stage including: } \\
\text { increasing costs as the technology and complexity increase progressively during the latter phases of implementation (Rao et al., } \\
\text { 2003). } \\
\text { the structure and level of management can insufficient (Chan \& Swatman, 2004). } \\
\text { a failure to adapt to the pace of rapid growth (Kaplan \& Haenlein, 2010). } \\
\text { a failure to manage negativity and critical comments (Ward \& Ostrom, 2006; Kaplan \& Haenlein, 2010). } \\
\text { a failure to adequately control the system (Damsgaard and Scheepers, 1999; Duane \& Finnegan, 2003; Kaplan \& Haenlein, 2010). }\end{array}$ \\
\hline $\begin{array}{l}\text { Benchmark } \\
\text { Variables }\end{array}$ & $\begin{array}{l}\text { Different technologies are in different stages, requiring different management strategies (Gibson \& Nolan, 1974). Each growth stage } \\
\text { can be measured using a variety of benchmark variables which define these management strategies including: } \\
\text { seven Ss: strategy; structure; systems; staff; style; skills; super-ordinate goals (Galliers \& Sutherland, 1991; Damsgaard \& } \\
\text { Scheepers, 1999). } \\
\text { five factors: task; objective; direction/involvement; methodological emphasis; planning context (Earl, 1989). } \\
\text { six key indicators: description; architecture; people and processes; value added; cost drivers; limitations (Hinrichs, 1997). } \\
\text { nine benchmark variables: data; architecture; stability of production environment; warehouse staff; users of warehouse; impact on } \\
\text { users' skills and jobs; use of warehouse ; organisational impacts; costs and benefits (Watson et al., 2001). } \\
\text { five growth types: strategy/objectives; focus; structure; management involvement; technology types/applications (Chan \& Swatman, } \\
2004) \text {. } \\
\text { six domains: strategic alignment; governance; methods; IT; people; culture (de Bruin and Roseman, 2005). } \\
\text { six critical success factors: experience; resources; process; measurement; commitment; culture (Forrester, 2012). }\end{array}$ \\
\hline
\end{tabular}

Gottschalk and Solli-Sæther (2010: 284) proposed that the suggested stage model is 'the initial stage model' in SoG modelling as it integrates 'ideas from both research and practice' and is derived from existing research and insights gleaned from practitioners. Using this approach, Gottschalk and Solli-Sæther (2010) developed a suggested stage model for e-Government operability. In the context of this study, the authors apply this technique to this study and following extensive reviews of 4 decades (1974-2014) of SoG research, as well as a review of social media research and practitioner insight across multiple domains, develop a suggested stage model for managing an SMBP, as shown in Table 3. While Gottschalk and Solli-Sæther (2010: 284) based their practitioner insights on 'informal discussions with researchers and practitioners in the government sector of Norway', the authors decided to use social media to gain a broader spread of practitioner insight from webinars (Bradley, 2010; Langlois, 2011), blogs (Goffi, 2011; Hamnett, 2011), YouTube interviews (Kawasaki, 2013) and practitioner reports (Bughin et al., 2011; Fenwick et al., 2010; ISACA, 2010; Williams et al., 2010). Four benchmark variables (strategy, focus, structure, and management) derived from the analysis of extant SoG models, as shown previously in Table 2, were applied to define management strategies at each stage. 
Table 3 A suggested stage model for managing a social media business profile (SMBP)

\begin{tabular}{|c|c|c|c|c|}
\hline Stage & Strategy & Focus & Structure & Management \\
\hline $\begin{array}{l}\text { 1. Experimentation } \\
\text { and Learning }\end{array}$ & $\begin{array}{l}\text { It is experimental with } \\
\text { every department doing } \\
\text { their own thing. }\end{array}$ & $\begin{array}{c}\text { Announcing launch of SMBP, posting } \\
\text { a number of comments, images and } \\
\text { videos, and providing some product/ } \\
\text { service information. }\end{array}$ & $\begin{array}{c}\text { Individual or } \\
\text { departmental drive. }\end{array}$ & $\begin{array}{l}\text { None or very little } \\
\text { involvement. }\end{array}$ \\
\hline 2. Rapid Growth & $\begin{array}{l}\text { It is coordinated across } \\
\text { all departments by } \\
\text { management, and a } \\
\text { number of goals and } \\
\text { objectives have been } \\
\text { established. } \\
\text { It is formalised and }\end{array}$ & $\begin{array}{l}\text { Consumer-centric focus. Efforts } \\
\text { aimed at increasing internal and } \\
\text { external awareness. Customers } \\
\text { are encouraged to connect, follow, } \\
\text { like, recommend, and comment, on } \\
\text { products and its services. }\end{array}$ & $\begin{array}{l}\text { Bottom-up widespread } \\
\text { user participation } \\
\text { coupled with top-down } \\
\text { management. }\end{array}$ & $\begin{array}{l}\text { Support and } \\
\text { Encourage. }\end{array}$ \\
\hline 3. Formalisation & $\begin{array}{l}\text { controlled across the } \\
\text { company, with a strategy } \\
\text { aligned with the business } \\
\text { plan. Staff adhere to an } \\
\text { established set of rules. }\end{array}$ & $\begin{array}{c}\text { Planning, strategy, governance, } \\
\text { and alignment with overall business } \\
\text { strategy. }\end{array}$ & $\begin{array}{l}\text { A more centralised } \\
\text { corporate driven model } \\
\text { to coordinate efforts. }\end{array}$ & $\begin{array}{l}\text { Controlled by } \\
\text { management. }\end{array}$ \\
\hline $\begin{array}{l}\text { 4. Consolidation and } \\
\text { Integration }\end{array}$ & $\begin{array}{l}\text { It is very well integrated } \\
\text { with key business } \\
\text { processes across the } \\
\text { company, and it is driving } \\
\text { a fundamental change in } \\
\text { how we do business. }\end{array}$ & $\begin{array}{c}\text { Optimisation of processes and } \\
\text { creating scale. Fundamental business } \\
\text { change. Pursue alignment with } \\
\text { external partners/suppliers. Co- } \\
\text { creation / ideation, crowdsourcing } \\
\text { emerge. }\end{array}$ & $\begin{array}{l}\text { Extension of corporate } \\
\text { model to integrate } \\
\text { external partners, } \\
\text { suppliers, customers, } \\
\text { communities, experts, } \\
\text { etc. Micro-outsourcing of } \\
\text { activities may also occur. }\end{array}$ & $\begin{array}{l}\text { Shared by } \\
\text { management / } \\
\text { staff. }\end{array}$ \\
\hline $\begin{array}{l}\text { 5. Institutional } \\
\text { Absorption }\end{array}$ & $\begin{array}{l}\text { It is embedded into the } \\
\text { core of what we do, } \\
\text { and how we do it, from } \\
\text { customers to suppliers, } \\
\text { from internal partners to } \\
\text { external partners. }\end{array}$ & $\begin{array}{l}\text { De-facto application for key business } \\
\text { tasks. Enterprise-wide social media } \\
\text { technologies for the entire workforce } \\
\text { Generate new/reengineer existing } \\
\text { business models. }\end{array}$ & $\begin{array}{l}\text { Aimed at customers, } \\
\text { suppliers and partners, } \\
\text { as business connectivity } \\
\text { is transformed to } \\
\text { establish wider business } \\
\text { relationships. }\end{array}$ & $\begin{array}{l}\text { Shared by } \\
\text { management / staff } \\
\text { or decentralised. }\end{array}$ \\
\hline
\end{tabular}

According to Gottschalk and Solli-Sæther (2010: 284), empirical testing is essential to ensure that the 'contents of stages are developed in an iterative cycle involving dominant problems that seem different at various stages'. Gottschalk and Solli-Sæther (2010) suggest that empirical analysis of stage models ultimately results in revised stage models. Thus, the suggested stage model only forms a platform for empirical testing and further refinement. While Gottschalk and Solli-Sæther (2010: 285) only use 'two cases to test their suggested stage model for e-government interoperability', the authors of this study adopt a mixed methodology consisting of four data collection methods to develop the conceptual stage model, including the following:

- An online survey was conducted; 103 Irish organisations from 20 industries responded. The targeted industries included Financial Services, Banking and Insurance; Retail; Manufacturing and Engineering; Health and Pharmaceuticals; ICT Hardware, Software and Telecommunications; Government and Public Services; Agriculture, Forestry and Fisheries; human resources (HR) and Recruitment; Professional and Scientific Services; and Transportation, Logistics and Warehousing.

- An online review of each organisation's SMBP predominantly consisting of blogs, Facebook, Twitter and Linkedln activities, as well as engagement with YouTube, Slideshare, Prezi, Pinterest, etc. This is similar to efforts by Parveen (2012), who engaged in website/social media analysis.

- Follow-up telephone interviews were conducted with those who agreed to participate further in the study; 60 organisations (58.25\% of respondents) agreed to a telephone interview; and

- Field studies in 10 organisations using interviews with senior management.

According to Gottschalk and Solli-Sæther (2010: 284), the conceptual stage model should clearly 'illustrate the content characteristics of each stage, as well as significant differences between stages where preceding and following stages have different kinds of dominant problems'. A common method to empirically test the stages is to form a 'description of the stages of growth' and to request management to 'indicate which stage most closely describes the present situation or status in their company' (Gottschalk and Solli-Sæther, 2010: 284). Using this technique, the authors used the stage descriptions from the suggested stage model (Step 1) to test for the existence and characteristics of the stages before developing the conceptual stage model (Step 2). To identify the dominant problems associated with the stages, the authors adopted the same approach as Gottschalk and Solli-Sæther (2010) and Kazanjian (1988), whereby survey respondents and interviewees were requested to consider the dominant problems and identify the stage(s) at which they occur. 


\section{FINDINGS}

\section{Step 1: findings from the suggested stage model}

Having reflected on the research into SoG models and after a review of existing social media research and practitioner insight across multiple domains in the literature review, the authors hypothesise that an organisation's SMBP evolves through five distinct stages, as shown in Table 3, namely, (i) experimentation and learning; (ii) rapid growth; (iii) formalisation; (iv) consolidation and integration; and (v) institutional absorption.

\section{Experimentation and learning}

Verheyden et al. (2010) reveal that social media was only recently adopted and is still evolving, and that its diffusion is restricted to external communication and public relations (PR). Levina and Yavetz (2013) report that 58\% of organisations are in the early stages of adopting social media. Social media adoption in most organisations is a grassroots effort, which is often just as effective as a formal pilot programme (McKinsey, 2007). Typical activities at this stage involve creating a basic SMBP on one or two social media platforms, announcing the organisation's arrival in the social media space, posting a number of comments, images and videos, and providing some product/ service information (Forrester, 2012; McKinsey, 2007). The experimentation and learning stage may initially be departmental/function driven or the work of a single individual in the marketing or PR team (Aral et al., 2013; Jacobs and Nakata, 2010), or it may be outsourced (Aral et al., 2013).

\section{Rapid growth}

Social media adoption experiences rapid growth, and organisations have difficulty adapting to the pace (Kaplan and Haenlein, 2010). Organisations may have been induced to use social media by pressures from competitors, trading partners and customers (Parveen, 2012). Use may expand from marketing to enhancing customer relationships, reputation management, value and brand equity, digital advertising, ideation (Kim and Ko, 2011) and establishing networks with business partners, while product/service innovation may also emerge (Meske and Stieglitz, 2013). As 'social media provide an efficient and accessible means of encouraging and supporting team members working together on shared objects' (Zeiller and Schauer, 2011: 1), staff may focus on task-driven processes and on implementing early processes to manage them (Forrester, 2012). Internal communication can emerge, enabling teams to share tasks, information and knowledge (Zeiller and Schauer, 2011). However, organisations may be wary of using social media to share in-house information (Verheyden et al., 2010).

\section{Formalisation}

As adoption matures, the need for organisations 'to integrate their social media strategies with their overall strategy' becomes more important (Aral et al., 2013: 8). However, responsibility is a problem at this stage because of the varying tools, ease of use and creation, duality of workplace and personal use, and lack of a strategic plan (Jacobs and Nakata, 2010). Thus, Munene and Nyaribo (2013: 149) contend that organisations need to 'develop vibrant, participative and agreeable policies to guide social media participation at work when trying to deal with challenges that arise from such participation so as employees understand implications of their actions concerning the boundary between personal and work boundaries'. Verheyden et al. (2010) also found that developing a social media policy is positively linked to staff attitudes towards social media adoption.

\section{Consolidation and integration}

Significant process improvements can be achieved through efficient social networking and organisational connectivity (Chivee et al., 2008). Thus, organisations are increasingly deploying social media internally to enhance their knowledge management and intra-firm collaboration efforts (Benbya and Van Alstyne, 2010; Zeiller and Schauer, 2011) and to transform the relationship and norms of behaviour among organisations, staff and consumers (Aral et al., 2013). This environment represents a shift that requires the development of new strategies and tactics (Godes et al., 2005). Social media may also transform how organisations engage with staff, enabling them to create dynamic relationships with remote experts (Archak 2010), to crowdsource new ideas (di Gangi and Wasko 2009) or to engage in micro-outsourcing (Goldman et al., 2011; Paolacci et al., 2010). 


\section{Institutional absorption}

Organisations can use social media to develop new business models when they reach a higher level of maturity (Jacobs and Nakata, 2010), enhancing and transforming virtually every business process and function (Gossieaux and Moran, 2010). Social media enables a systematic approach to improving business processes, which becomes a key priority (Forrester, 2012). As the organisation becomes more experienced and the technology matures, the usage pattern shifts, and social media becomes the de facto application of choice for performing certain key business tasks (Forrester, 2012). At this stage, staff integration reaches a point where organisations implement enterprise-wide social media for the entire workforce, empowering staff to regularly use social media (Forrester, 2012).

Thus, having adopted Gottschalk and Solli-Sæther's (2010) five-step stage modelling process and having conducted a thorough review of the literature and reflection on practitioner insight in order to develop a suggested stage model (Step 1) for SMBP implementation and management, the authors were in a position to empirically test this model in order to develop a conceptual stage model (Step 2).

\section{Step 2: findings from the conceptual stage model}

As shown in Figure 2,78.64\% of the 103 organisations that responded identify with the stages as portrayed in the suggested stage model. However, $21.36 \%$ did not identify with any of the stages. As previously discussed, it is essential for a stage model to conceptualise the dominant problems and empirical analysis is required to conceptualise in which stage(s) these problems occur (Gottschalk and Solli-Sæther, 2010). Thus, Figure 3 outlines the top six dominant problems reported by organisations that identified with Stages 1-4. Only two organisations indicated they were in Stage 5, thus the authors believe that the evidence is insufficient to robustly identify Stage 5 or its dominant problems. The authors believe that as this longitudinal study progresses through Steps 3-5 of Gottschalk and Solli-Sæther's (2010) stage modelling process, an increasing number of organisations may emerge that are consistent with Stage 5, thus enabling future clarification of this stage and its dominant problems. Further exploration of these findings in follow-up telephone and personal interviews with senior managers and senior staff members in 60 organisations (58.25\% of 103 organisations who agreed to participate further in the study) revealed a number of additional insights into organisational adoption of social media.

Figure 2 Evidence of stages from empirical testing of the suggested stage model.

\begin{tabular}{|c|c|c|}
\hline It is experimental with every department doing their own thing. & $25.24 \%$ & 26 \\
\hline $\begin{array}{l}\text { tis coordinated across all departments by management, and a number of goals and objectives } \\
\text { have been established. }\end{array}$ & $26.21 \%$ & 27 \\
\hline $\begin{array}{l}\text { tis formalised and controlled across the company, with a clear social media strategy aligned } \\
\text { with the business plan, and everyone adheres to a well-established set of rules and } \\
\text { procedures. }\end{array}$ & $16.50 \%$ & 17 \\
\hline $\begin{array}{l}\text { tis very well integrated with key business processes across the company, and it is driving a } \\
\text { fundamental change in how we do business. }\end{array}$ & $8.74 \%$ & 9 \\
\hline $\begin{array}{l}\text { is is completely embedded into the core of what we do, and how we do it, from customers to } \\
\text { supplers, from internal partners to external partners. }\end{array}$ & $1.94 \%$ & 2 \\
\hline None of the above. & $21.36 \%$ & 22 \\
\hline
\end{tabular}


Figure 3 Dominant problems with social media adoption in Stages 1-4.

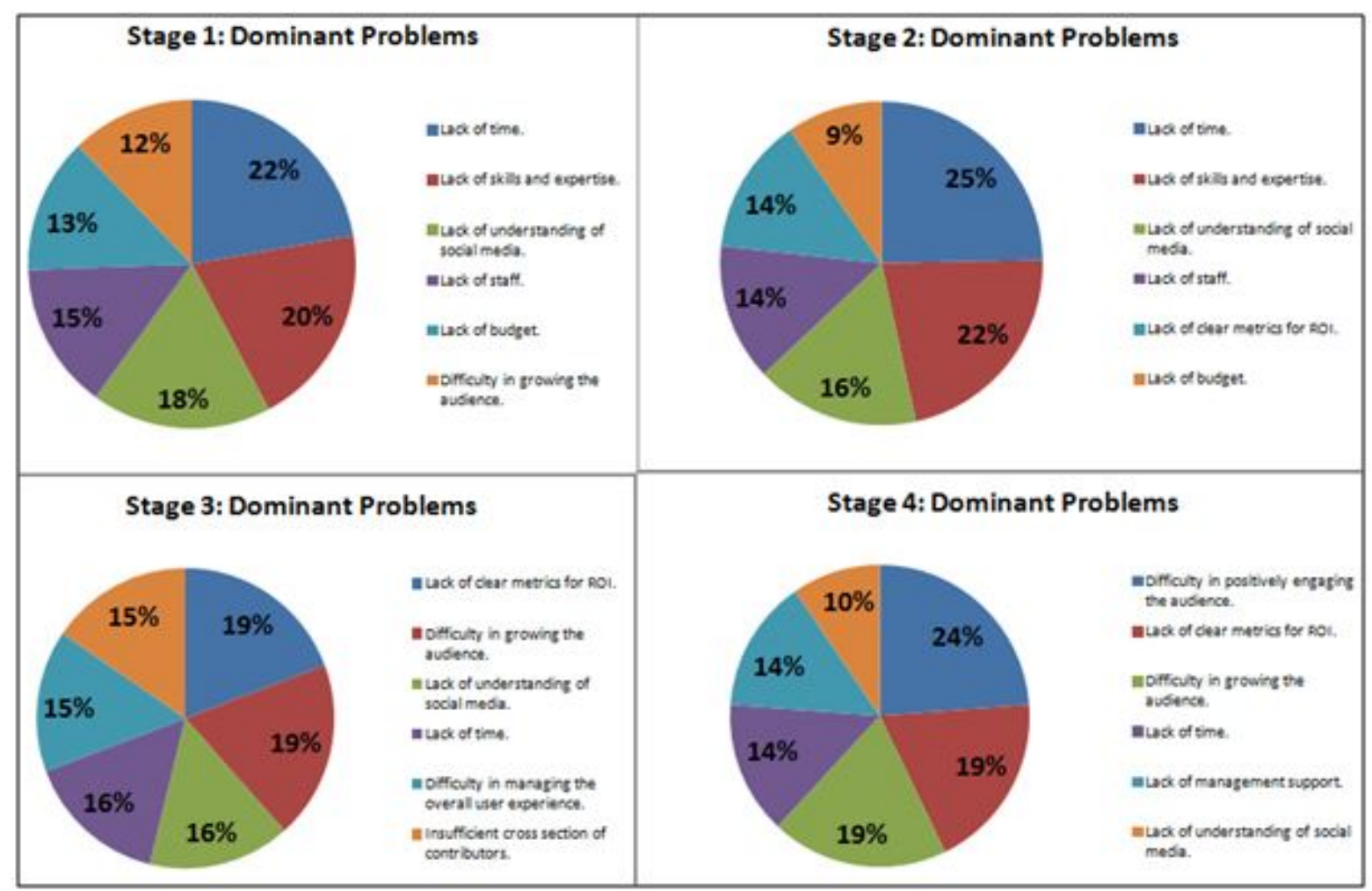

\section{Stage 0: exploration}

Respondents from 14 of the 22 organisations (21.36\%) that did not recognise any of the stages of growth in the suggested stage model contend that their organisation is in a stage that precedes Stage 1 (experimentation and learning). In effect, the respondents contend that there is a Stage 0. Follow-up interviews with all of the respondents reveal that many of the organisations first learn of social media from members of staff or, sometimes, a senior manager who uses social media for personal purposes. Some of these respondents even suggested that they had first learned of social media from their children prior to their own personal use. This personal use then evolved over time into considering ways in which it could be used for business purposes. This was then typically followed by online research of the types of social media being used in a business context, how they are being used by other organisations and to what effect. Some of the respondents suggested that increased personal use of the Internet, Apps, Web 2.0 and social media over the past decade has blurred the lines between personal use and organisational adoption and learning when it comes to emerging technologies, and that in many cases, it is personal use that leads to organisational use, as evidenced by Facebook personal profiles leading to the development of Facebook business pages.

Interestingly, the dominant problems in Stage 0, which are in reality inhibitors to adoption, are very similar to the dominant problems experienced by organisations in Stage 1, as shown in Figure 4, with one exception: the organisation's need to identify clear metrics for return on investment (ROI) prior to adoption. Although Stage 0 organisations cite the lack of time, skills, expertise, budget, understanding and staff as dominant problems, the lack of clear metrics appears to be a significant inhibitor (third-ranked dominant problem) to the initial adoption of social media in these organisations. According to one sales manager, 'I'm well aware of the possibilities with social media, but this is considered to be an extremely time consuming activity and if we can't show clear metrics for ROI, it won't get approval on a business level'. This is an important finding when one considers that the lack of clear metrics for ROI does not rank very highly in the top six dominant problems until Stage 3 (ranked first) in organisations that have already adopted social media. Although lack of clear metrics for ROI is also identified as a dominant problem in Stage 2 in organisations that have already adopted social media, it only ranks as the fifth most dominant problem. 
Figure 4 Dominant problems with social media adoption in Stage 0.

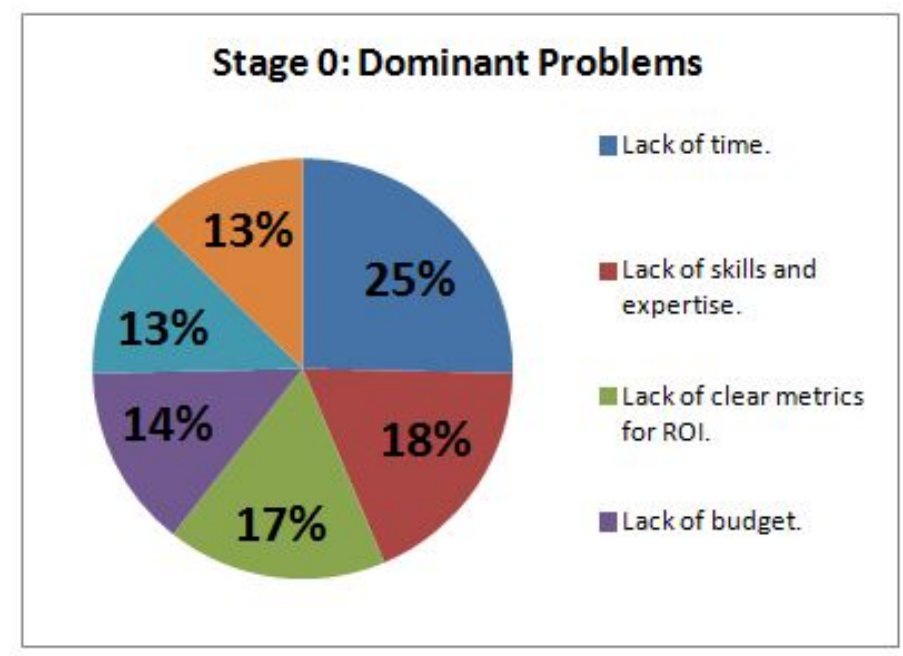

Thus, the findings reveal that the stage model for managing an organisation's SMBP should be revised to include a Stage 0 entitled Exploration, which considers personal use as a possible precursor to organisational use. However, the authors conclude that this Stage 0 is not like the 'Dormant stage' proposed by Forrester (2012: 4), which is overtly negative, only focussing on 'resistance to any use of social technologies due to unwillingness to participate or analysis paralysis'. Interestingly, interviewees in Gottschalk and Solli-Sæther's (2010: 286) study suggested the inclusion of a 'conceptual planning stage' preceding Stage 1, which was never adopted in their stage model of e-Government operability. However, a Stage 0 in SoG models is not entirely unusual as it has been previously noted in SoG models proposed by Jeffery and Leliveld (2004) and de Bruin et al. (2005).

\section{Stage 1: experimentation and learning and stage 2: rapid growth}

As shown in Figure 2, the majority of organisations (51.45\%) indicate that they are in Stage 1 or Stage 2 of the suggested stage model. Further discussions with the respondents reveal that rapid growth is not an appropriate descriptor of Stage 2. Instead, respondents suggest that Stage 2 is better described as 'direction and coordination' as it is through these types of management activities that rapid growth is enabled. Thus, the authors of this study undertook to revise the stage description in the conceptual stage model.

With respect to Stage 1, the majority of respondents indicate that initial development of the SMBP is driven by the Marketing Department or by an individual in the marketing function. It is then unsurprising that the top five uses reported by organisations at Stage 1 and Stage 2, as shown in Figure 5, relate to marketing (87 organisations), information sharing (73 organisations), advertising (67 organisations), PR (65 organisations) and communication (65 organisations). This is similar to the findings of Meske and Stieglitz (2013), who found that marketing-related activities drive early adoption of social media.

Forrester (2012) suggests that clarity of the social media strategy and objectives is essential for effective organisational adoption. Thus, the authors engaged in a thematic keyword analysis of each organisation's stated objectives for their SMBP, as clarified in Stage 2. This analysis reveals that increasing brand awareness (63 organisations) and driving sales (43 organisations) are the overwhelmingly stated key objectives. Only three organisations identified communication as part of their objective for using social media, and only one organisation identified customer feedback. Further analysis reveals that despite widespread use of the SMBP in Stage 1 and Stage 2, only 30 organisations (29.1\%) use social media to gather customer feedback. There also appears to be significant shortcoming with respect to analysis of customer feedback as shown in Figure 6, as only 17 organisations $(16.5 \%)$ do so, which is only $56 \%$ of the 30 organisations that actually gather feedback in the first instance. Overall, these results are a concern, as they seem to indicate that organisations still do not grasp (i) the enormous potential of using social media to better understand and engage with customers and (ii) the benefits of analysing customer feedback for better product/service design and delivery. This also lends support for Aral et al.'s (2013: 7) assertion 
that 'another important and, as yet, under researched area relates to the optimal social media tactics for consumers'. Organisations clearly need support to develop consumer-focussed social media strategies.

Figure 5 Evidence of SMBP use in Stages 1 and 2.

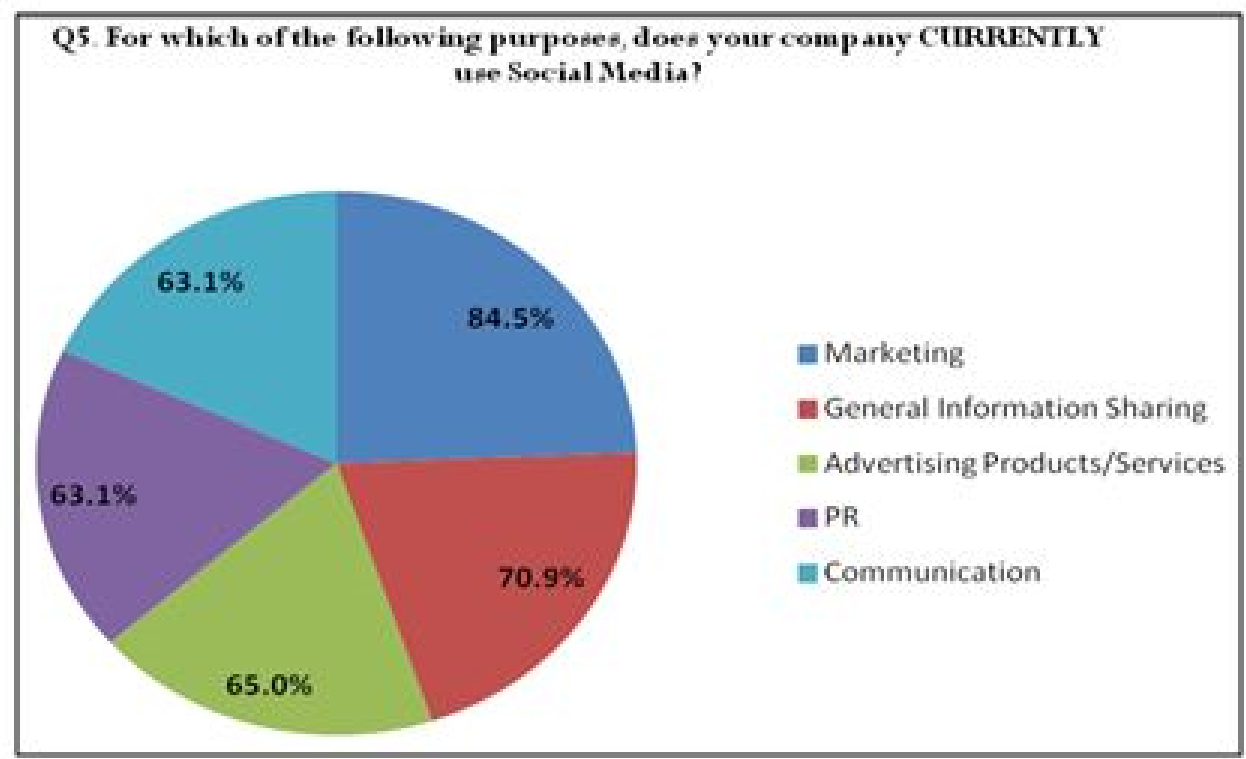

Figure 6 Evidence of customer feedback/analysis in Stages 1 and 2.

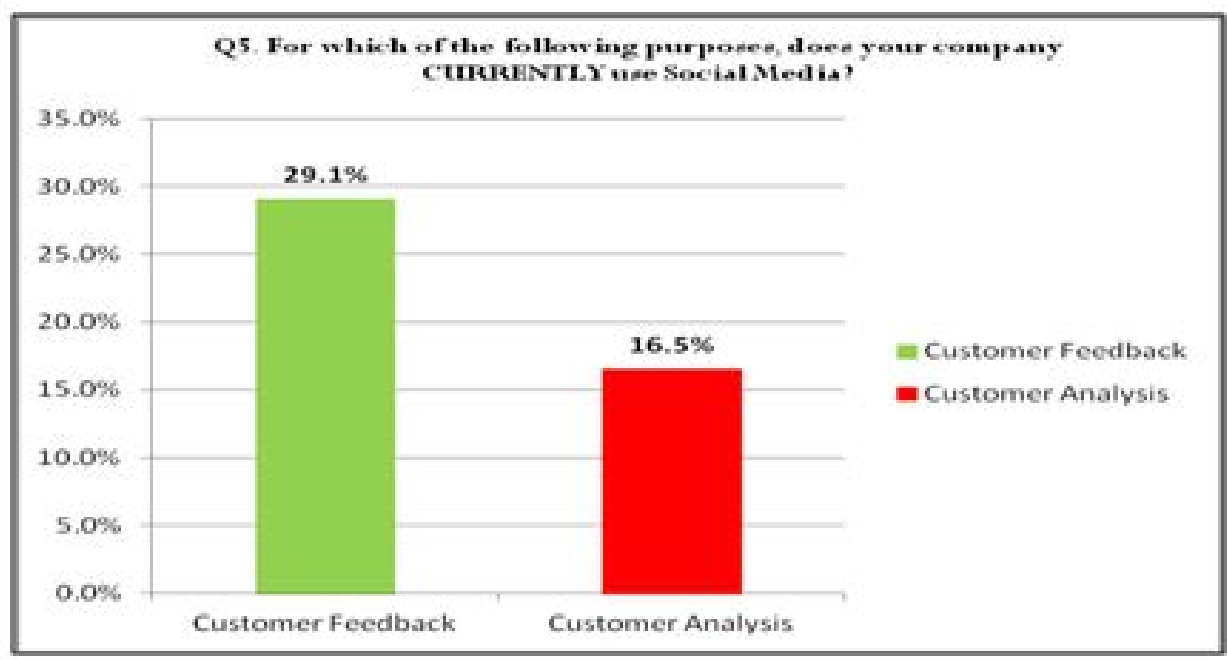

As shown previously in Figure 3, lack of time, skills, expertise and understanding of social media are the top three dominant problems in both Stage 1 and Stage 2, accounting for $>60 \%$ of the dominant problems in both stages. Interestingly, the lack of time, as well as lack of skills and expertise, increases in significance as dominant problems in Stage 2, while the lack of understanding diminishes, as organisations become more familiar with the technology. This lends credence to the proposition that Stage 1 is about experimentation and learning. Curiously, interviewees also indicate that this lack of knowledge, skills and expertise was a factor in the organisation's decision to participate further in this study: 60 organisations (58.25\%) agreed to participate further. Responsibility is also an issue at this stage, as many of the interviewees who worked on the initial adoption of social media believe it adversely affects 
their workload, and they no longer want the responsibility for it. This suggests that at this stage, social media requires dedicated knowledge experts to advance its adoption. This is also evident in the survey, as lack of time is the highest-ranked dominant problem and a lack of staff is the fourth-highest-ranked dominant problem in Stage 2. Respondents also suggest that this hinders any development of a social media strategy formally, or even informally, as staff know there is a lack of budget to implement it. In Stage 2, most organisations appear to overcome the difficulties experienced in growing the audience in Stage 1. However, the lack of clear metrics for ROI begins to become a problem in Stage 2, ranking as the fifth most dominant problem.

Interestingly, a number of organisations that indicate they are at Stage 2 of the suggested stage model reveal they are starting to develop social media strategies. However, many of these organisations are experiencing difficulties in devising strategies. In fact, 21 organisations have empowered just one person to devise the strategy for the entire company. This is not best practice according to Munene and Nyaribo (2013), who recommend a team/ group-based approach. This view is also expressed by one interviewee, who suggests that this approach results in a very one-dimensional perspective (i.e. solely based on marketing). According to the interviewee:

It is managed by one person who is establishing a model that will incorporate goals and objectives. At present the objective is limited to establishing our presence amongst our target market through Facebook, Linkedln and to some extent Twitter. We are overly focussed on getting our message out and not really listening to what our customers have to say.

Similarly, another interviewee remarks that lack of resources is a problem at this stage, stating: 'we have a clear strategy but we lack the ability to give it the full attention it requires due to lack of staff'. Lack of coordination may also be a significant issue at this stage, as one interviewee reveals that 'our company only reviews our social media presence once a year and it is largely managed by volunteers rather than being the sole responsibility of any individual or group'. One organisation had already outsourced its social media management, while an interviewee from another organisation suggests that 'we do not have the in-house skills so we are considering outsourcing our social media profile'. Incongruity and lack of coordination appear to a be a common theme in organisations that indicated they were in Stage 2 as many interviewees described their SMBP as 'patchy and incoherent', only 'updated sporadically' and 'ad hoc'. There also appears to be ambiguity and uncertainty over the purpose of the SMBP, and one interviewee suggests 'we are finding it difficult to keep coming up with relevant content'. These findings are consistent with the findings for Stage 1 and Stage 2 from the survey, as shown in Figure 3.

Evidence from the literature of previous SoG models indicate that use of technology is often a reliable indicator of the level of maturity (Chan and Swatman, 2004; Earl, 2000; Rao et al., 2003; Watson et al., 2001), and the authors believe that this evidence of use of the SMBP, coupled with the associated dominant problems, seem consistent with the organisations' maturity stages, as indicated by the respondents, i.e. respondents have accurately indicated the stage of maturity for their own organisation with respect to management and dominant problems of the SMBP in Stage 1 and Stage 2.

\section{Stage 3: formalisation}

Of the 103 organisations that responded to the initial survey, only 17 organisations (16.5\%) indicated that they have evolved to Stage 3 of the SoG model. This is quite surprising given the length of time that the respondents have been using social media in the organisation for business purposes, as shown in Figure 7. In fact, 69 organisations $(66.99 \%)$ have been using social media for $\geq 2$ years, and $28.82 \%$ have been using it for $\geq 4$ years, yet only nine organisations (10.68\%) have evolved to Stage 4 and only two organisations have evolved to Stage 5 . This seems to indicate that SMBP adoption can stagnate or slows considerably at this point in its evolution. This lends credence to the assertion by Barnes and Lescault (2011: 2) that adoption of social media by organisations 'has levelled off or fallen'.

However, one has to consider the dominant problems to shed some light on the reasons why adoption of the SMBP may stagnate in Stage 3. It is clear from interviews with senior management and senior staff in respondent organisations that once social media strategies are developed and linked to business strategies, metrics must be identified and measured. Interviews with respondents indicate that a lack of viable and reliable metrics to underpin the social media strategy greatly undermines efforts to secure funding and investment in the SMBP, as managements are unwilling to invest until the ROI can be measured. These assertions are underpinned by the results of the survey shown in Figure 3, which reveals that lack of clear metrics for ROI becomes a significant problem in Stage 3, 
ranking joint highest dominant problem. The other dominant problem in Stage 3, ranked as the joint highest, is that organisations report a difficulty in further growing the audience at this stage. It is thus clear that a failure to invest in social media adoption at Stage 3, due to a lack of clear metrics for ROI, has a significant negative impact on the organisation's ability to grow its audience using social media. This indicates that social media adoption can stagnate in Stage 3 without investment.

Discussion with respondents reveals excessive control by management, which traditionally is reported to stymie adoption of IS in typical formalisation/control stages (e.g. Gibson and Nolan, 1974; McKay et al., 2000), is not an issue in social media adoption. In fact, lack of understanding of social media appears to become a problem again at Stage 3, as there appears to be a lack of understanding of how to move ahead with the SMBP adoption. Bradley (2010) and Forrester (2012) describe this as business process disconnect. This may also be related to the fact that survey respondents report that there is a difficulty in managing the overall user experience and there is an insufficient cross section of contributors in Stage 3. This may be what Huang et al. (2011) refer to as monologue and a lack of stakeholder involvement. While lack of time is also a problem in Stage 3, it is not ranked as high as it is in Stage 1 and Stage 2.

Figure 7 Length of time organisations have been using social media.

Q3. When did you first start using Social Media in your organisation for business purposes?

\begin{tabular}{|c|c|c|}
\hline \multirow{2}{*}{$\begin{array}{c}\text { Answer Choices } \\
0.6 \text { months }\end{array}$} & \multicolumn{2}{|c|}{ Responses } \\
\hline & $5.83 \%$ & 6 \\
\hline 6.12 months & $7.77 \%$ & 8 \\
\hline $12-18$ morths & $8.74 \%$ & 9 \\
\hline 18.24 months & $10.68 \%$ & 11 \\
\hline$>2$ years & $20.39 \%$ & 21 \\
\hline$>3$ years & $17.48 \%$ & 18 \\
\hline$>4$ years & $12.62 \%$ & 13 \\
\hline$>5$ years & $16.50 \%$ & 17 \\
\hline Total & & 103 \\
\hline
\end{tabular}

\section{Stage 4: consolidation and integration and stage 5: institutional absorption}

Of the 103 organisational respondents, nine organisations (8.74\%) indicate they are in Stage 4 . Each of these organisations are engaged in a mix of social media-based activities that have surpassed its use as a marketing and PR tool, transforming its use to engage established customers in the co-creation of new products and services. Social media is also used in project management and research and development (R\&D), while also being used to source partners and suppliers. Interestingly, three of the organisations use social media for crowdsourcing, while one organisation is also engaged in crowdfunding. User-generated content (UGC) also features prominently in five of the organisations. The HR departments in seven of these organisations also use social media to identify skilled individuals for recruitment purposes. Six of the organisations also overhauled their website to embed social media content. An interviewee from one company, who indicated that they were at Stage 4 of the suggested stage model, suggests that different social media platforms attract different customers when revealing as follows: 'our SMBP is broad, focussing on Twitter, Google Ads, Blogging and Facebook. We find that we have attracted different types of consumers on Twitter/Facebook, so it works well. Our use of social media has also prompted us to develop a new website in order to integrate everything'. However, while integration is clearly evident in these organisations, consolidation also appears to occur. One interviewee cautions about trying to do too much too soon on social media, stating that they had abandoned some social media platforms and suggesting that the organisation had 
'learned the hard way that it is best to select only a few platforms once you have finished experimenting with the pros and cons. It is best to do these few well rather than to have too many and have no market penetration at all'.

The most dominant problem at this stage is a difficulty in positively engaging the audience $(24 \%)$. Although social media is often touted as an ideal interface to engage customers in co-creation and ideation, some of the organisations in Stage 4 of the suggested stage model indicate that they experienced a difficulty in positively engaging the audience. According to one interviewee:

you just can't open up the discussion to all customers on social media as you will just get too much noise and negativity in the feedback. We have learned that the hard way. You have to take an approach whereby you seek out valued opinions - those views on your company, your products, your services from the outside looking in views that make you sit up and think about the fundamentals of what you do, and how you do it. Social media is a great way to identify the power user, the critical influencer of other consumers of your product. It is these people you want to engage with in ideation and co-creation.

From another perspective, negative consumer feedback on social media can be interpreted positively as one interviewee describes how:

We hosted a preview of a new ad campaign on a secure page on our website. We invited our most active customers on Facebook to go to the site and provide us with feedback. It was fantastically negative - fantastic because we pulled the ad based on the negative feedback. We revised the campaign and the second set of reviews was far more positive from our customers. After we released it, it became one of our most successful advertising campaigns. We couldn't have done it without social media.

Lack of clear metrics for ROI (19\%) continues to be a significant problem for organisations in Stage 4. It is clear that much remains to be done in organisations and by researchers to develop clear metrics to measure the social media ROI. One interviewee states 'in our business we know we have to do social media but it's a real challenge to quantify precisely why'. Another interviewee alludes to the problem 'stemming from a lack of knowledge and skills in data analysis and social media metrics'. This lack of knowledge and understanding of social media metrics is also closely linked to the survey responses, which identify a lack of understanding as the sixth highest ranked dominant problem in Stage 4. Lack of management support is also identified for the first time as a dominant problem (ranked fifth highest) in the suggested stage model. Further discussion with organisations reveals that this typically pertains to 'management being a little in the dark with regard to how to further integrate social media into business processes', according to one interviewee.

Only two organisations (1.94\%) indicate that they are in Stage 5 . Thus, as previously stated the authors contend that there is insufficient data arising from this study to determine the existence or characteristics of Stage 5 or its dominant problems.

A conceptual stage model should clearly 'illustrate the content characteristics of each stage, as well as significant differences between stages where preceding and following stages have different kinds of dominant problems' (Gottschalk and Solli-Sæther, 2010: 284). Thus, having analysed the findings from the mixed-methodology research approach, the authors are better positioned to develop the conceptual stage model for managing an organisation's SMBP, as outlined in Table 4.

\section{CONCLUSIONS}

The emergence of the empirically validated conceptual SoG Model for managing an SMBP partially addresses the 'Management and Organisation' element of Aral et al.'s (2013: 4) 'Social Media and Business Transformation Framework for Research'. There is strong evidence to support the proposed SoG model, with $78.64 \%$ of respondents (81 organisations) identifying with the stages. Descriptively, the model can be used to evaluate the use, maturity, and paths of evolution of an organisation's SMBP. Prescriptively, the model can be used to formulate an appropriate strategy to integrate social media with business strategy, and by highlighting the dominant problems, it provides organisations with an opportunity to anticipate and plan for their management. This research not only contributes to academia by enhancing the existing 4 decades of knowledge on SoG models, extending it to the management 


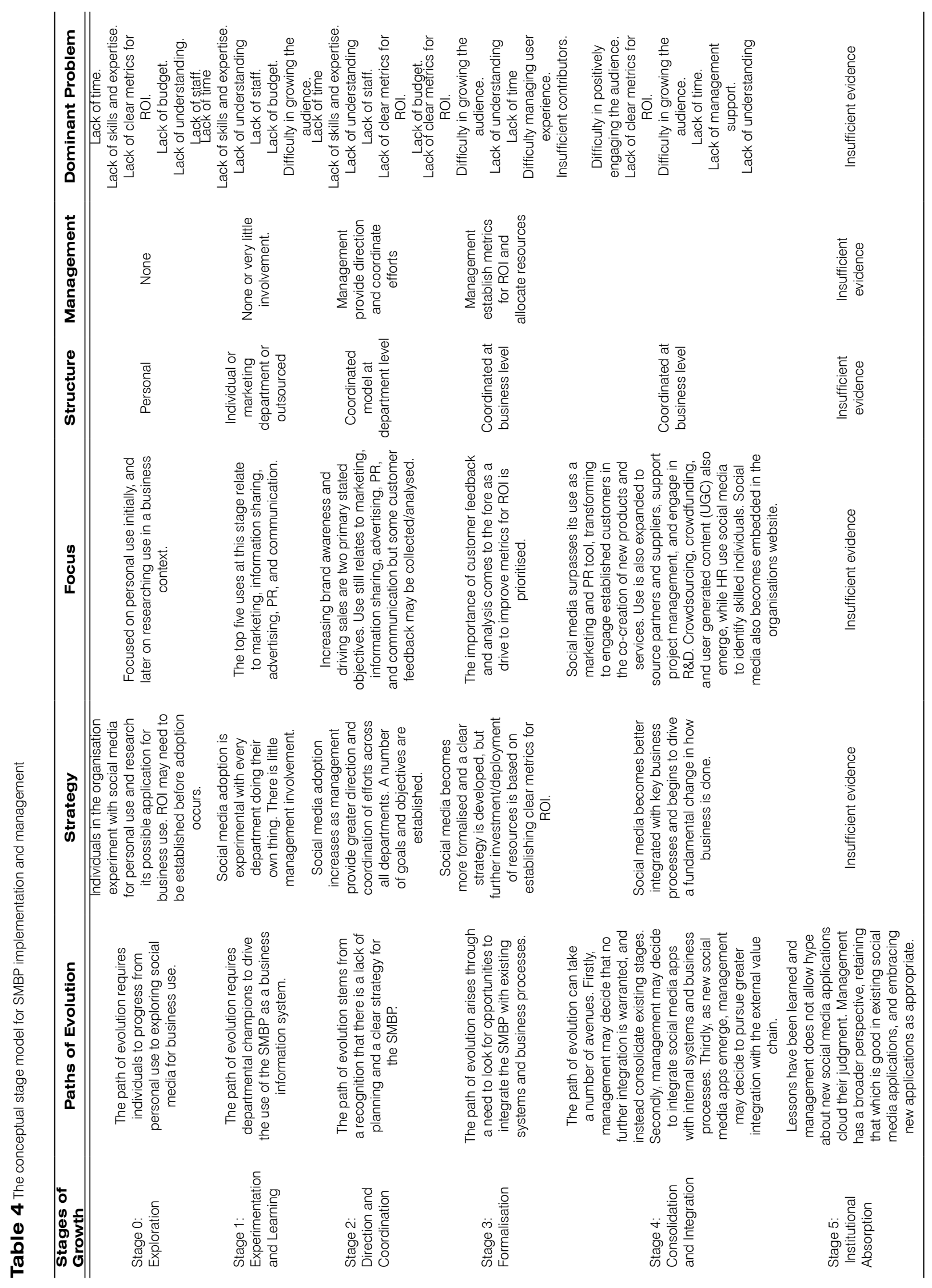


of social media in an organisational context, but this study is also a critical piece of research from a practitioner perspective, as organisations struggle to devise tactics and strategies to manage social media adoption and use. In addition to developing the conceptual SoG Model, a number of additional key findings emerged:

\section{Very slow adoption of social media}

Most organisations (51.45\%) indicate that they are in Stage 1 or Stage 2 of the SoG model. This is similar to findings by Levina and Yavetz (2013), who report that $58 \%$ of organisations are still in early stage of social media adoption. The top five uses of social media at Stage 1 and Stage 2 relate to marketing, information sharing, advertising, PR, and communication. Increasing brand awareness and driving sales are the overwhelmingly stated key objectives of social media for the organisations. In an earlier study, Verheyden et al. (2010) found that diffusion was restricted to external communication and PR. This is a concern as it appears that organisational adoption of social media has failed to progress beyond basic use, and there is little evidence of the 'growing importance of social media as a strategic tool among organisations', as suggested by Parveen (2012: 3). Thus, it appears, as suggested by Aral et al. (2013), that organisations are still barely scratching the surface of the true capabilities of social media.

\section{Levelling off of social media adoption}

Only $16.5 \%$ of organisations indicate they are in Stage 3, while $8.74 \%$ indicate they are in Stage 4 of the SoG Model. This is despite the fact that $67 \%$ of organisations have been using social media for $\geq 2$ years and $29 \%$ have been using it for $\geq 4$ years. This indicates that social media adoption stagnates or slows considerably, leading to a levelling off in Stage 3. Furthermore, only two organisations indicate they are in Stage 5. This levelling off affects the organisations' ability to grow the audience using social media, and hence this is a dominant problem in Stage 4. This confirms Barnes and Lescault's (2011: 2) hypothesis that adoption of social media by organisations 'has levelled off or fallen'.

\section{Failure to capture and/or analyse metrics}

Organisations clearly do not grasp the enormous potential of using social media to better understand and engage with customers, and the benefits of analysing customer feedback for better product/service design and delivery. Only $30 \%$ of organisations indicate that they gather customer feedback via social media and only $16.5 \%$ analyse customer feedback. This is clearly a vicious circle for many organisations, as a lack of metrics is a dominant problem in Stage 3 and Stage 4, and many organisations will not invest further in social media unless ROI can be measured. The failure to capture and analyse social media metrics may stem from the fact that organisations are beset by dominant problems such as a lack of understanding of social media, a lack of time, and a lack of skills and expertise of social media, which account for $>60 \%$ of the dominant problems in the first three stages. Overall, there is an apparent lack of understanding of what to do with social media at Stage 3, which affects the progress to Stage 4, and it supports Aral et al.'s (2013: 8) contention that as social media adoption matures, organisations must 'integrate social media strategies with their overall strategy'. The apparent centralisation of responsibility for social media in organisations with one or two individuals in marketing departments is undermining social media adoption. This refutes Bott et al.'s (2009) assertion that problems may dissipate as social media matures and organisations overcome the newness factor.

\section{Social media is still evolving}

Social media is 'a moving target' (Aral et al., 2013: 4), and given the rapid development and ever changing technological capabilities of social media applications and the growing pervasiveness of smartphone-enabled social media access, the proposed conceptual stage model will be subject to change as social media technologies progress. This is similar to Watson et al.'s (2001) data warehousing SoG model, which was modified due to changes in the underlying technology. This is also consistent with Gottschalk and Solli-Sæther's (2010) assertion that execution of the stage modelling process results in a revised stage model.

\section{Future research}

Given that social media adoption is in its early stages and very few of the 103 respondent organisations appear to be in Stage 4 and only two in Stage 5, the authors are currently engaged in a 2-year longitudinal case-study research in 60 organisations. The primary purpose of this work is to continue to deploy Gottschalk and SolliSæther's (2010) stage modelling process by developing theoretical (Step 3), empirical (Step 4) and revised (Step 
5) stage models. In addition, the authors are completing a comparative study with two different Canadian sample groups (i.e. 70 organisations in the Ottawa business community randomly selected and 100 organisations listed on the Toronto Stock Exchange selected through stratified sampling). These two studies will enable the authors to further refine the model while also enabling comparative studies between Irish and Canadian organisations. The authors encourage other researchers to reflect upon the issues highlighted in this study and to consider SoG models as a valid approach to developing management strategies for social media adoption in organisations.

\section{References}

Adelakun, O. (2004). 'IT outsourcing maturity model', in Proceedings of the 12 European Conference on Information System (ECIS), Paper 25, Turku, Finland, June 14-16.

Aggarwal, R., Gopal, R., Sankaranarayanan, R. and Vir Singh, P. (2011). 'Blog, blogger, and the firm: Can negative employee posts lead to positive outcomes'. Information Systems Research, 23: 2, 306-322.

Aguenza, B.B. and Mat Som, A.P. (2012). 'A conceptual analysis of social networking and its impact on employee productivity'. IOSR Journal of Business and Management, 1: 2, 48-52.

Aral, S., Dellarocas, C. and Godes, D. (2013). Introduction to the special issue: Social media and business transformation: A framework for research'. Information Systems Research, 24: 1, 3-13.

Archak, N. (2010). 'Money, glory and cheap talk: Analyzing strategic behavior of contestants in simultaneous crowdsourcing contests on TopCoder.com', in M. Rappa, P. Jones, J. Freire and S. Chakrabarti (eds), Proceedings of the 19th International Conference of the World Wide Web, New York: ACM Press, 21-30.

Archambault, A. and Grudin, J. (2012). 'A longitudinal study of Facebook, Linkedln, \& Twitter Use', in Proceedings of the ACM SIGCHI Conference on Human Factors in Computing Systems, Texas, May 5-10.

Baltatzis, G., Ormrod, D.G. and Grainger, N. (2008). 'Social networking tools for internal communication in large organisation: Benefits and barriers', in Proceedings of the 19th Australian Conference on Information Systems (ACIS), Christchurch, December 3-5.

Barnes, N.G. (2012). 'Potential liability of social media in higher education marketing'. Journal of Higher Education Theory and Practice, 12: 5, 54-59.

Barnes, N.G. and Lescault, A.M. (2011). Social Media Adoption Soars as Higher-Ed Experiments and Reevaluates Its Use of New Communication Tools. UMass Dartmouth Centre for Marketing Research, July 11. http://www.umassd.edu/ media/umassdartmouth/cmr/studiesandresearch/ higherEd.pdf [Accessed 1 June 2015].

Benbasat, I., Dexter, A.S., Drury, D.H. and Goldstein, R.C. (1984). 'A critique of the stage hypothesis: Theory and empirical evidence'. Communications of the ACM, 27: 5, 476-485.

Benbya, H. and Van Alstyne, M. (2010). 'How to find answers within your company'. MIT Sloan Management Review, 52: 2, 65-75.

Bott, J., Montagno, R. and Lane, J. (2009). Emerging Media: Prevalence and Impact in the Workplace. http://cms.bsu.edu/ Academics/CentersandInstitutes/BBR/ /media/ DepartmentalContent/MillerCollegeofBusiness/ BBR/Publications/Emerging\%20Media\%20Report. ashx [Accessed 1 June 2015].

Bradley, A. (2010). How to Develop A Rational and Realistic Social Media Strategy. www.gartner. com/it/content/1447000/1447015/november_16_ develop_a_social_media_strategy_abradley.pdf [Accessed 1 June 2015].

Brugha, C. (1998). A Generic Change Management Decision Model: Putting Galliers and Sutherland's Stages of Growth Model into a Broader Context. http://mis.ucd.ie/Members/cbrugha/ pubs/Brugha $\% 20$ Generic $\% 20$ Change $\% 20$ Management $\% 20$ Decision $\% 20$ Model $\% 20$ UKAIS98.pdf [Accessed 1 June 2015].

Bughin, J., Hung Byers, A. and Chui, M. (2011). 'How social technologies are extending the organisation'. McKinsey Quarterly, November. http://www. mckinseyquarterly.com/How_social_technologies_ are_extending_the_organisation_2888 [Accessed 1 June 2015].

Chan, C. and Swatman, P.M.C. (2004). 'B2B E-commerce stages of growth: The strategic imperatives', in Proceedings of the 37th Hawaii International Conference on System Sciences (ICSS), 1-10.

Chivee, L.L., Hamilton, B.A. and Cowan, E. (2008). 'Networking the way to success: online social networks for workplace and competitive advantage'. People and Strategy, New York, 31: 4, 40-47.

Damsgaard, J. and Scheepers, R. (1999). 'A stage model of intranet technology implementation and 
management', in Proceedings of the 7th European Conference on Information Systems (ECIS), Copenhagen Business School, Copenhagen, Denmark, June 23-25.

de Brí, F. (2009). 'An E-government stages of growth model based on research within the irish revenue offices'. Electronic Journal of E-Government, 7: 4, 339-348.

de Bruin, T., Freeze, R., Kaulkarni, U. and Rosemann, M. (2005). 'Understanding the main phases of developing a maturity assessment model', in B. Campbell, J. Underwood, and D. Bunker (eds), Proceedings of the Australasian Conference on Information Systems (ACIS), Nov.30-Dec. 2, Australia, NSW, Sydney.

di Gangi, P.M. and Wasko, M. (2009). 'Steal My Idea! organisational adoption of user innovations from a user innovation community: A case study of dell ideastorm'. Decision Support Systems, 48: 1, 303-312.

Duane, A. and Finnegan, P. (2003). 'Managing empowerment and control in an intranet environment'. Information Systems Journal, 13: 2, 133-158.

Earl, M.J. (1989). Management Strategies for Information Technology, Burr Ridge, IL: Irwin.

Earl, M.J. (2000). 'Evolving the e-business'. Business Strategy Review, 11: 2, 33-38.

Fenwick, N., Cliff Condon, Leaver, S., Spivey Overby, C. and Worthington, B. (2010). The ClOs Guide to Establishing a Social Media Policy. http://www. forrester.com/The+ClOs+Guide+To+Establishing +A+Social+Media+Policy/fulltext/-/E-RES56771? docid $=56771$ andsrc $=59690$ pdf [Accessed 1 June 2015].

Forrester. (2012). Accelerate Your Social Maturity. Christine Spivey Forrester. http://www.forrester. com/Accelerate+Your+Social+Maturity/fulltext/-/ERES59690 [Accessed 1 June 2015].

Galliers, R.D. and Sutherland, A.R. (1991). 'Information systems management and strategy formulation: The stages of growth model revisited'. Journal of Information Systems, 1: 2, 89-114.

García, V.V., Fernández Vicent, E.J. and Aragonés, L.U. (2013). Maturity model for IT service outsourcing in higher education institutions'. International Journal of Advanced Computer Science and Applications (IJACSA), 4: 10, 39-45.

Ghachem, L. (2006). 'Maturity of electronic commerce: A review of the principal models', in Proceedings of ICEB + eBRF 2006, Global Conference on Emergent Business Phenomena in the Digital Economy, Frontiers of E-Business Research.
Paper CR1057, ISSN: 1683-0040, Dec. 2, Tampere, Finland.

Gibson, C.F. and Nolan, R.L. (1974). 'Managing the four stages of EDP growth'. Harvard Business Review, 52: 1, 76-88.

Godes, D., Mayzlin, D., Chen, Y., Das, S., Dellarocas, C., Pfeiffer, B., et al. (2005). 'The firm's management of social interactions'. Marketing Letters, 16: 3, 415-428.

Goffi, C. (2011). Social Media: A „Mission Critical” Solution for Your Contact Center. www.avaya.com/ blogs/archives/2011/06/social-media-a-missioncritical-solution-for-your-contact-center.html [Accessed 1 June 2015].

Goldman, M., Little, G. and Miller, R.C. (2011). 'Collabode: Collaborative coding in the browser', in M. Cataldo, C. de Souza, Y. Dittrich, R. Hoda, and H. Sharp (eds), Proceedings of the 4th International Workshop on Cooperative and Human Aspects of Software Engineering, New York: ACM Press, 65-68.

Gossieaux, F. and Moran, E. (2010). The Hyper-Social Organisation, New York: McGraw-Hill.

Gottschalk, P. and Khandelwal, V.K. (2004). 'Stages of growth for knowledge management technology in law firms'. Journal of Computer Information Systems, 44: 4, 111-124.

Gottschalk, P. and Solli-Sæther, H. (2006). $\square$ Maturity model for IT outsourcing relationships $\square$. Industrial Management \& Data Systems, 106: 2, 200-12.

Gottschalk, P. and Solli-Sæther, H. (2010). 'The modelling process for stage models'. Journal of Organisational Computing and Electronic Commerce, 20, 279-293.

Hamnett, J. (2011). Crisp vs. Apple Retail. www. peoplemanagement.co.uk/pm/articles/2011/10/ crisp-v-apple-retail.htm [Accessed 1 June 2015].

Helms, R.W. (2010). 'Social media adoption in the product software industry'. Journal of Theoretical and Applied Electronic Commerce Research, 5: 1, 16-30.

Hinrichs, R.J. (1997). Intranets: What's the Bottom Line? New Jersey: Prentice Hall.

Hong, J. (2012). 'The state of phishing attacks'. Communications of the ACM, 55: 1, 74-81.

Huang, Y., Vir Singh, P. and Srinivasan, K. (2011). 'Crowdsourcing blockbuster ideas: A dynamic structural model of ideation', in Proceedings of the Thirty Second International Conference on Information Systems (ICIS), Paper 19, Shanghai, December 6.

Huff, S.L., Munro, M.C., Martin, B.H. and Sibley, E.H. (1988). 'Growth stages of end-user computing'. Communications of the ACM, 31, 542-550. 
ISACA. (2010). Social Media: Business Benefits with Security, Governance and Assurance Perspectives. White Paper. June 7. http:// www.isaca.org/Knowledge-Center/Research/ ResearchDeliverables/Pages/Social-MediaBusiness-Benefits-and-Security-Governance-andAssurance-Perspectives.aspx [Accessed 1 June 2015].

Jacobs, A. and Nakata, K. (2010). 'Evolving the social business: A look at stages of growth for web 2.0 integration with business activities', in Proceedings of the IWCSC ,10 First Interdisciplinary Workshop on Communication for Sustainable Communities, Sao Paolo, Brazil, September 26-29.

Janssen, M. and van Veenstra, A.F. (2005). 'Stages of growth in e-government: An architectural approach'. The Electronic Journal of e-Government, 3: 4, 193200.

Jayasuriya, R. (1993). 'Stages of growth in end-user computing: Applications in the health sector of developing countries'. Journal of Information Technology, 8, 151-159.

Jeffery, M. and Leliveld, I. (2004). 'Best practices in IT portfolio management'. MIT Sloan Management Review, 45: 3, 41-49.

Kaplan, A.M. and Haenlein, M. (2010). 'Users of the world, unite! The challenges and opportunities of social media'. Business Horizons, 53, 59-68.

Kawasaki, G. (2013). 'How to use social media as an evangelist for your business and here's how I did it!', MIT Enterprise Forum, San Diego. https://www. youtube.com/watch?v=rZCDGBnC058 [Accessed 1 June 2015].

Kazanjian, R.K. (1988). 'Relation of dominant problems to stages of growth in technology-based new ventures', Academy of Management Journal, 31: 2, 257-279.

Kim, A.J. and Ko, E. (2011). 'Do social media marketing activities enhance customer equity? An empirical study for a luxury fashion brand'. Journal of Business Research, 65: 10: 1480-1486.

King, J. and Kraemer, K. (1984). 'Evolution and organisational information systems: An assessment of Nolan's stages model'. Communications of the ACM, 27: 5, May.

King, W.R. and Teo, T.S.H. (1997). 'Integration between business planning and information systems planning: Validating a stage hypothesis'. Decision Science, 28, 279-308.

KPMG. (1997). Electronic Commerce Research Report, London, UK: KPMG Management Consulting.

Langlois, C. (2011). Customer Experience Without Borders - Social Media in Financial Services. http:// www.backbase.com/knowledge/webinars/socialmedia-in-financial-services-09062011 [visited on 1 June 2015].

Layne, K. and Lee, J. (2001). 'Developing fully functional e-government: A four stage model'. Government Information Quarterly, 18, 122-136.

Levina, O. and Yavetz, I.V. (2013). 'Use of social software in e-business: A cross-sectional, crosscountry study', in Proceedings of the Nineteenth Americas Conference on Information Systems, Chicago, Illinois, August 15-17.

Li, P., Yu, Y. and Fielden, K. (2013). 'Social media trends in small businesses'. Asia Pacific Journal of Business and Management, 4: 2, 55-70.

Lingling, H. (2011). 'Strategic planning of IS in an organisation', in Proceedings of the Asia-Pacific Power and Energy Engineering Conference, March 25-28, Wuhan, China, 1-4.

Magal, S.R., Carr, H.H. and Watson, H.J. (1988). 'Critical success factors for information center managers'. MIS Quarterly, 22, 413-425.

McFarlan, F.W. and McKenney, J.L. (1982). 'The information archipelago: Gaps and bridges'. Harvard Business Review, 60: 5, September.

McKay, J., Prananto, A. and Marshall, P. (2000). 'E-business maturity: The SOG-E model', in Proceedings of the Australian Conference on IS (ACIS), Brisbane, Australia.

McKinsey. (2007). 'How businesses are using web 2.0', McKinsey Quarterly, March. http://www. mckinseyquarterly.com/How_businesses_ are_using_Web_20_A_McKinsey_Global_ Survey_1913 [Accessed 1 June 2015].

Meske, C. and Stieglitz, S. (2013). 'Adoption and use of social media in SMEs', in F. Harmsen and H. Proper (eds), Practice-Driven Research on Enterprise Transformation - Notes in Business Information Processing, Berlin: Springer, 151, 61-75.

Munene, A.G. and Nyaribo, Y.M. (2013). 'Effect of social media participation in the workplace on employee productivity'. International Journal of Advances in Management and Economics, 2: 2, 141-150.

Nesbit, T. (2011). 'Social media: In the workplace and patterns of usage'. International Journal of Interdisciplinary Social Sciences, 5: 9, 61-80.

Nikhil, M., Sharon, O. and Anju, M. (2007). 'Infosys technologies: Improving organisational knowledge flows'. Journal of Information Technology, 22, 456-464.

Nolan, R.L. (1979). 'Managing the crisis in data processing'. Harvard Business Review, 5: 2, 115126.

Paolacci, G., Chandler, J. and Ipeirotis, P.G. (2010). 'Running experiments on Amazon Mechanical 
Turk'. Judgment and Decision Making, 5: 5, 411419.

Parveen, F. (2012). 'Impact of social media usage on organisations', in Proceedings of the Pacific Asia Conference on Information Systems, Paper 192. http://aisel.aisnet.org/pacis2012/192 [Accessed 1 June 2015].

Piskorski, M.J. (2011). 'Social strategies that work'. Harvard Business Review, 89: 11, 116-123.

Rao, S.S., Metts, G. and Monge, C. (2003). 'Electronic commerce development in small and medium sized enterprises: A stage model and its implications'. Business Process Management Journal, 9: 1, 1132.

Rayport, J.F. and Jaworski, B.J. (2002). Introduction to E-Commerce, Boston: McGraw Hill.

Rocha, A. (2012). 'Maturity models for management of IS and technologies in healthcare'. International Journal of Business Information Systems, 9: 2, 189-201.

Verheyden, M., Goeman, K., Pierson, J. and Philips, K. (2010). 'Adoption of social media in the workplace: An explorative study of use, perceptions and policies within Flemish professional organisations'. Journal of Theoretical and Applied Electronic Commerce Research, 5: 1, 31-45.
Ward, J.C. and Ostrom, A.L. (2006). 'Complaining to the masses: The role of protest framing customercreated complaint websites'. Journal of Consumer Research, 33: 2, 220-230.

Watson, H., Ariyachandra, T. and Matyska, R.J. Jr. (2001). 'Data warehousing stages of growth'. Information Systems Management, Summer, 4250.

Weber, L. (2011). Everywhere: Comprehensive Digital Business Strategy for the Social Media Era, New Jersey: John Wiley and Sons.

Williams, D., Gownder, J.P. and Wiramihardja, L. (2010). Case Study: IHG, Chase and Consumers CoCreate a New Rewards Credit Card. http://www. forrester.com/Case+Study+IHG+Chase+And+Co nsumers + CoCreate $+A+\mathrm{New}+$ Rewards + Credit $+\mathrm{Ca}$ $\mathrm{rd} /$ fulltext/-/E-RES58315?docid $=58315$ andsrc $=59$ 690pdf [Accessed 1 June 2015].

Zeiller, M. and Schauer, B. (2011). 'Adoption, motivation and success factors of social media for team collaboration in SMEs', in Proceedings of the 11th International Conference on Knowledge Management and Knowledge Technologies, i-KNOW,11, Article No. 4, Graz, Austria, September 7-9, New York, USA: ACM. 